\title{
VICTOR FERREIRA DO AMARAL E SILVA: DO OIKOS A SCHOLÉ (1862-1878) ${ }^{1}$
}

\author{
Névio de Campos ${ }^{2}$ \\ Universidade Estadual de Ponta Grossa (UEPG)
}

\section{RESUMO:}

Este artigo objetiva analisar a trajetória escolar de Victor Ferreira do Amaral e Silva, enfatizando sua educação primária e secundária cursadas no Colégio Jacob Müller (Curitiba) e no Colégio Abílio (Rio de Janeiro). Discutir a trajetória escolar de Victor do Amaral e Silva mostra-se relevante para compreender o percurso típico dos filhos das elites paranaenses do século XIX. Apoia-se no conceito de trajetória de Bourdieu para problematizar o percurso escolar de Victor do Amaral articulado aos contextos social, político, cultural (educacional) e econômico, privilegiando uma abordagem próxima ao modelo representacional, no qual a experiência desse personagem sintetiza várias outras biografias. Desse modo, por meio da trajetória de Victor do Amaral foi possível compreender o movimento da elite política e econômica da Província do Paraná ao longo da segunda metade do século XIX que ao pôr seus filhos nas escolas de prestígio buscava prepará-los para ingressar no ensino superior e garantir suas presenças nos espaços públicos e privados de maior relevo do cenário paranaense.

Palavras-chave: História da educação; instrução primária; instrução secundária.

\section{VICTOR FERREIRA DO AMARAL E SILVA: FROM OIKOS TO SCHOLÉ (1862-1878)}

\begin{abstract}
:
The article analyzes Victor Ferreira do Amaral e Silva's school history, highlighting his primary and secondary education at Jacob Müller School (Curitiba) and Abílio School (Rio de Janeiro). The discussion of his schooling is important if one is to understand the usual course of studies undertaken by the sons and daughters of the $19^{\text {th }}$ century élite in the State of Paraná. This study bases itself on Bourdieu's concept of what a trajectory is and uses this as a debate on the path taken in Victor do Amaral's schooling linking it to the social, political, cultural (educational) and economic contexts, emphasizing the approach which is closest to the representational model in which the experience of this person synthesizes several other biographies. In this way, using Victor do Amaral's educational path, it was possible to understand the activity of the political and economic élite in the Province of Paraná throughout the second half of the 19th century which, by placing its children in prestigious schools, intended to prepare them for university as well as guaranteeing a place for them in public and private sectors of greater prestige in the scenario of Paraná.

Keywords: History of education; primary schooling; secondary schooling.
\end{abstract}

\section{Introdução}

A obra biográfica intitulada Victor Ferreira do Amaral e Silva (o reitor de sempre), ${ }^{3}$ de Eduardo Corrêa Lima contempla um conjunto de memórias, relatórios da Universidade do Paraná e da Faculdade de Medicina, publicações de discursos, teses, artigos de Victor do Amaral e homenagens prestadas a ele. É uma espécie de tributo à ação desse personagem que por muito tempo exerceu funções públicas no Estado do Paraná. ${ }^{4} \mathrm{~A}$ 
trajetória de Victor do Amaral é substantiva para entender o percurso típico dos filhos das elites paranaenses. Investigar a trajetória de um indivíduo não se resume a um interesse biográfico ou ao culto a personalidades de destaque em determinado campo.

Neste texto, o modo de abordar a posição de Victor do Amaral é herdeiro da proposição de Pierre Bourdieu:

Diferentemente das biografias comuns, a trajetória descreve a série de posições sucessivamente ocupadas pelo mesmo escritor em estados sucessivos do campo literário, tendo ficado claro que é apenas na estrutura de um campo, isto é, repetindo, relacionalmente, que se define o sentido dessas posições sucessivas, publicação em tal ou qual revista, ou por tal ou qual editor, participação em tal ou qual grupo etc. (BOURDIEU, 1996, 71-72).

Analisar o percurso de Victor do Amaral que prevê sua origem familiar (oikos) e sua inserção na vida escolar (scholé) pode parecer uma abordagem que privilegia um olhar para o caminho, para um cursos. Porém, tal impressão é apenas aparente, pois pactuamos com a crítica de Bourdieu à ilusão biográfica, a qual consiste em desconstruir a tese de que a vida é em si uma história - um caminho que percorremos e que deve ser percorrido, um trajeto, uma corrida, um cursos, uma passagem, uma viagem. A pretensão dessa análise se distancia da acepção tradicional de biografia, onde a categoria trajetória é apropriada de modo indiferente às particularidades circunstanciais e aos acidentes individuais no fluxo das realidades sociais. Neste artigo objetiva-se estabelecer uma síntese entre o local-global, o singular-universal. Logo, procura romper com o rótulo da história acontecimental história linear e anedótica, bem como com a história estrutural. Aqui se privilegiará uma abordagem próxima ao modelo representacional, no qual a trajetória de Victor do Amaral não ocorre em função do que há de singular na sua trajetória, mas particularmente porque sintetiza várias outras biografias. Nessa abordagem o individual não é visto em oposição ao social - o social é produto da ação de indivíduos em suas relações com outros indivíduos. Pensa-se na trajetória de Victor do Amaral para, por meio dela, percorrer em diversos espaços e tempos as relações nas quais ela se inscreveu.

A análise da trajetória de Victor Ferreira do Amaral do oikos a scholé tem maior significado se estiver articulada aos contextos social, político, cultural (educacional) e econômico. Essa metodologia está longe de assumir uma visão linear da trajetória dessa personalidade, pois nada é mais problemática do que escrever a história de um indivíduo imaginando uma identidade coerente, uma trajetória dada a priori. Essa assertiva se aproxima do postulado de Norbert Elias ao afirmar que as trajetórias constituídas são resultados de "algo que não foi planejado nem foi intenção de qualquer um desses indivíduos, mas emergiu a despeito de suas intenções e ações" (ELIAS, 1993, p. 140).

Tais observações introdutórias reafirmam que a preocupação é descaracterizar o sentido de expressar uma visão teleológica da trajetória de Victor do Amaral. Ao contrário, por meio da reconstituição de aspectos da trajetória dessa personalidade, objetiva-se contribuir para compreender a história da educação dos filhos dos fidalgos do Paraná.

\section{O infante Victor Ferreira do Amaral e Silva: da Lapa a Curitiba}

Victor Ferreira do Amaral nasceu na Fazenda Santana, no Município da Lapa, então Vila do Príncipe, em 09 de dezembro de 1862, cidade situada a aproximadamente 60/70 quilômetros da capital do Paraná. Lapa originou-se de um pequeno povoado fundado às margens da antiga Estrada da Mata (ligava Rio Grande do Sul a São Paulo, 
desempenhando importante papel no progresso do interior paranaense), que era apenas uma parte do histórico Caminho de Sorocaba, por onde circulavam tropas vindas do Rio Grande do Sul com destino a feira de Sorocaba. A primeira denominação era Pouso de Capão Alto (1731). Em 13 de junho de 1797, o Pouso foi elevado à categoria de Freguesia, quando o Capitão Francisco Teixeira Coelho (português) assumiu a função de comandante. Em 06 de junho de 1806 foi elevada a vila, recebendo o nome de Vila Nova do Príncipe. Em 1870 passou a ser sede de Comarca, assumindo a função de Juiz Antonio Cândido Ferreira de Abreu. Por fim, em 07 de março de 1872 foi elevada à categoria de município e cidade, com território desmembrado de Curitiba e passando a se chamar Lapa.

Victor do Amaral era filho de Seraphim Ferreira de Oliveira e Silva e de Julia M. do Amaral e Silva. A família de Victor era formada por doze irmãos contando com ele. Sua família era pertencente ao grupo da elite agrária dos Campos Gerais, uma região ampla, hoje composta por mais de duas dezenas de cidades. Na segunda metade do século XIX, essa região fornecia as principais lideranças políticas do Paraná, o que se materializou no predomínio dos interesses da oligarquia agrária. Sua organização econômica consubstanciava-se na criação e comércio de gado e na produção agrícola (erva-mate).

O início do século XVIII marcou a ocupação da região dos Campos Gerais. Inicialmente foi ocupada por famílias originárias de São Paulo, Santos e Paranaguá (primeira cidade do Paraná). No final do oitocentos quase toda a área dos Campos Gerais estava povoada, embora escassamente, pois existiam propriedades muito grandes para comportar a pecuária expansiva. A pecuária passou a dominar a economia regional. Quem possuía recursos, investia-os na compra de gado no Rio Grande do Sul, para revender na feira de Sorocaba. Surgia, então, o tropeiro, intermediário entre o criador e o comprador.

$\mathrm{Na}$ avaliação de Carlos Vicente Ferreira,

São os tropeiros de 'tiro longo e os de tiro curto' ou 'malas nos tentos', com capital suficiente para sustentar toda a longa operação desde a compra do gado no sul, a recuperação nos Campos Gerais e a revenda em Sorocaba. Os segundos, às vezes, simplesmente reduziam-se a condutores das tropas. (FERREIRA, 1996, p. 41).

A baixa na produção de metais preciosos em Minas Gerais representou a desagregação do sistema comercial dos fazendeiros (tropeiros) dos Campos Gerais. Não obstante, com a expansão da produção de café em São Paulo, no segundo quartel do século XIX, "o tropeirismo ganha novos mercados e conhece o apogeu, em meados do século passado [XIX]" (FERREIRA, 1996, p. 41). Esse negócio promissor se manteve até o final do oitocentos quando foi criada a rodovia Centro-Sul do país (Minas Gerais, Rio de Janeiro e São Paulo), o que implicou na redução da procura de muares. Em termos quantitativos é exemplar a passagem de: "a feira de Sorocaba, que ainda, em 1860 negociava 100 mil animais, não movimentava mais que 5 mil nos anos finais do século passado [XIX]. Com o ciclo dos tropeiros arquivado, a economia ficou estagnada" (FERREIRA, 1996, p. 41). De acordo com as observações de Rui Wachowicz, "o dono das tropas não era um homem pobre. A formação de uma tropa requeria quantias razoáveis, sendo a maioria de seus proprietários homens abastados e de destaque" (WACHOWICZ, 1977, p-72).

Os proprietários dos campos do planalto curitibano, desde o segundo quartel do oitocentos, iniciaram a criação de gado, ou seja, os tropeiros transformaram-se em criadores de gado. De "zona de passagem a princípio, os Campos Gerais [segundo planalto paranaense] tornaram-se, também logo depois, zona produtora" (FERREIRA, 1996, p. 43). Foi no planalto curitibano que iniciou a produção de erva-mate, produto que manteve a economia paranaense por mais de um século, logo se espalhando por cidades dos Campos 
Gerais, como por exemplo, Lapa. A produção da erva-mate paranaense passou a atender aos mercados argentinos. Na avaliação de, "esse produto de exportação vai se transformar em esteio da economia paranaense, sobretudo no período provincial. Foi uma época de ouro. Houve períodos em que o produto chegou a representar $85 \%$ da economia da província" (WACHOWICZ, 1977, p. 96). A erva-mate, produzida nos planaltos paranaenses passava pelo processo industrial no litoral, logo, a oligarquia de Morretes, Paranaguá e Antonina se beneficiava de maior parte do lucro. A ascensão da oligarquia litorânea representou a desagregação da oligarquia campeira.

Até a metade do século XIX, o grupo ligado ao latifúndio dos Campos Gerais controlava a maior parte do poder econômico e do poder de governo no Paraná. Havia o grupo do litoral, atrelado ao comércio da erva-mate, porém com poder muito menor. Esse cenário começou a mudar a partir da metade do mesmo século, caracterizado por um processo de desagregação dos negócios agrários, bem como pelo crescimento substancial da industrialização da produção do mate. No plano econômico, houve retrocesso da força da oligarquia agrária e avanço da potência da oligarquia do litoral do Paraná. Na esfera política, as disputas estavam abertas, com expressiva força majoritária dos latifundiários no Congresso Paranaense, o que permitia a manutenção de diretrizes a favor desse grupo. No entanto, a ação de Ildefonso Correia (Barão do Serro Azul), principal liderança do Partido Conservador e representante da oligarquia do litoral (comerciantes de erva-mate) consistiu na representação típica contra os mandos dos políticos dos Campos Gerais.

Em termos tipológicos é possível sustentar que os fazendeiros, também conhecidos por senhores dos Campos Gerais, estavam associados aos latifúndios agropastoris, pecuária bovina e invernagem e comércio de muares provenientes do Rio Grande do Sul. Estavam atrelados também ao trabalho escravo, à regulamentação moral dos mercados de abastecimento, ao incentivo à imigração européia, ao monopólio da representação política, pois os especialistas (bacharéis, médicos, engenheiros) - filhos dos fazendeiros ocupavam grande parte dos empregos públicos e dos cargos de representação política da Província.

Victor do Amaral tinha origem familiar de fazendeiros e produtores de erva-mate do Paraná. Sua família fazia parte de um grupo que ocupava o topo da pirâmide social da população paranaense. Na autobiografia Minha infância escolar, Victor do Amaral assim enunciou sua origem social:

Meu saudoso pai tinha uma fazenda, no município da Lapa, cuja principal produção era a herva-mate; negociava também, como tropeiro, conduzindo, auxiliado por seus escravos, tropas de muares trazidas do Rio Grande do Sul, para levar à feira de Sorocaba, com escalas pelas invernadas dos Campos Gerais. (SILVA, 1982, p. 23).5

A origem familiar e social de Victor do Amaral expressava o modelo típico da oligarquia agrária: proprietária de fazenda, produtora de erva-mate, pecuarista e comerciante de muares, proprietária de escravo, base de apoio aos políticos dos fazendeiros. Foi desse ambiente social, político e econômico que saíra Victor do Amaral. Do ponto de vista social era herdeiro de uma condição abastada, mesmo que os negócios da oligarquia agrária passassem por profunda crise na segunda metade do século XIX. Associado ao capital social acumulou forte capital político, já que esse grupo tinha forte presença na política da Província do Paraná. Sua família tinha vínculo estreito com nada menos que David dos Santos Pacheco, Barão dos Campos Gerais. As duas famílias eram muito amigas. O pequeno Victor era afilhado do Barão e da Baronesa. Esse título expressava sua condição de liderança da oligarquia agrária paranaense. O Barão dos 
Campos Gerais foi o fundador do Partido Liberal, partido das elites agrárias que se contrapunha ao Partido Conservador, partido da oligarquia do litoral paranaense.

A divergência entre tais grupos não se dava por programas partidários, mas interesses setoriais de cada camada. Na avaliação de Luiz Carlos Ribeiro, "a alternância no poder que se dava na Corte repetia-se aqui [Paraná]. Os conservadores estavam no governo desde 1886" (RIBEIRO, 1982, p. 71). No entanto, "em junho de 1889, com a queda do gabinete conservador de João Alfredo e a ascensão do gabinete liberal do Visconde de Ouro Preto assume, no Paraná, o principal líder liberal, Jesuíno Marcondes de Oliveira [...]". Marcondes, em conjunto com o Barão dos Campos Gerais e Manuel Alves de Araújo (genro do Barão) formavam "a mais poderosa oligarquia local durante todo o período da província do Paraná" (RIBEIRO, 1982, p. 71). Por outro lado, "o Partido Conservador era chefiado por Manuel Antonio Guimarães (Visconde de Nácar) e por Manuel Francisco Correia (senador do Império), ambos pertencentes também a poderosas famílias que no litoral controlavam o comércio importador e exportador da erva-mate" (RIBEIRO, 1982, p. 71). Acrescentamos que o Partido Conservador teve na trajetória de Ildefonso Correia outra importante liderança política que se contrapôs ferozmente aos liberais. ${ }^{6}$

Victor do Amaral ainda era criança quando saiu da Lapa e dirigiu-se a Curitiba. Ele narra que "em 1872, quando eu contava apenas 9 anos de idade, vim para Curitiba em companhia de meu avô José Ferreira Bueno, em três dias de viagem, a cavalo por estrada pouco viável, transitada por tropas de bestas, carregadas com cestos de herva-mate, destinada aos engenhos de Morretes e Antonina" (SILVA, 1982, p. 23). Em Curitiba, ingressou no colégio do professor alemão Jocob Müller ${ }^{7}$ para concluir o Ensino Primário e iniciar o Ensino Secundário. A autobiografia de Victor do Amaral não faz referência aos primeiros anos de sua escolarização na cidade da Lapa. Nesse período, na sua cidade natal existiam duas cadeiras de instrução pública primária para meninos e uma para meninas. Em 1871, havia uma escola particular mista em sua cidade. Embora não indique seu início escolar, presumimos que estudou nessa escola particular da Lapa.

No ano em que Victor do Amaral se dirigiu a Curitiba existiam dezoito escolas particulares primárias no Paraná, dentre elas a de Jacob Müller. Essa Escola era de instrução primária e secundária. Pelo ensino secundário recebia subvenção pública do Estado. Entretanto, a partir de 1871 deixou de receber as verbas públicas, por conseqüência, suas atividades de ensino secundário se esvaíram. De acordo com o relatório do Inspetor Geral João Franco de Oliveira Souza, "a escola de Müller se reduziu ao ensino primário (internato) e aulas avulsas de instrução secundária (externato) ministrados pelo próprio diretor e proprietário" (RELATÓRIO..., 1873, p. 13).

De acordo com Maria Cecília de Oliveira,

No período provincial foi famoso o colégio do professor Jacob Müller, criado em Curitiba em 1868 [1869]. Subvencionado pelo Governo, o colégio manteve aulas de ensino primário e secundário, em regime de internato e externato. Seus alunos pertenciam à famílias de destacada posição social, muitos dos quais tiveram participação ativa na vida econômica, política e cultural do Paraná [...]. A organização do colégio de Jacob Müller e o padrão social de sua clientela garantiram o prestígio que desfrutou nos anos de seu funcionamento. (OLIVEIRA, 2006, s. p.).

Pela indicação do Inspetor Franco de Oliveira o Colégio de Jacob Müller não gozava do prestígio apontado por Cecília de Oliveira. O relatório do referido inspetor sustenta que os colégios particulares com reconhecido prestígio eram o Serapião (Morretes) e o Instituto Paranaense (Ponta Grossa). Essa observação do inspetor precisa ser 
relativizada, pois se Ponta Grossa contava com um prestigioso colégio de ensino primário/secundário, era de se esperar que Victor do Amaral fosse encaminhado a essa cidade e não a Curitiba. Como se tratou do primeiro colégio particular de instrução secundária da capital era plausível que a elite paranaense enviasse seus filhos ao Colégio Müller.

Sem entrar no mérito se o Colégio de Müller gozou de prestígio ou não, é possível afirmar que a sua presença na instrução secundária foi efêmera, logo é pouco provável que tenha atendido um grupo considerável da elite dominante e dirigente do Paraná. Porém, por curto tempo foi uma opção para uma parcela da elite paranaense. A julgar pela decisão dos pais de Victor Amaral que, optaram por enviá-lo ao Abílio da Corte para cursar o ensino secundário, é provável que esse prestígio fora superestimado. Outro elemento que contribui para relativizar a presença desse colégio é a avaliação de Bento Fernandes de Barros, Inspetor Geral da Instrução Pública do Paraná, para o qual "o collégio subvencionado apresenta ainda em sua organização elementos diversos que significam a sua impotência para satisfazer a missão a que é destinado" (RELATÓRIO..., 1871, p. 24). Além disso, "esse facto [ausência de professor de latim, francês e geometria] é a um tempo a significação legal da fraqueza do mesmo estabelecimento que a província subvenciona, e da ausência de um pensamento systematico na organização do ensino" (p. 24). Por fim, arrematou o Inspetor que "o estado actual do Collegio não é promettedor de sucesso" (p. 25).

Naquele contexto eram poucos os colégios particulares existentes na Capital do Paraná. Não existiam os colégios católicos. Esses iniciaram em 1896 com o Colégio São José. Os Colégios Franciscanos e Santa Maria foram fundados em 1902 e 1925 respectivamente. A elite paranaense contava com poucas opções de educação escolar no oitocentos. O Colégio de Jacob Müller foi um dos projetos direcionados à elite dominante e dirigente do Paraná, embora tenha passado por inúmeras dificuldades. É possível afirmar que, a saída de crianças e jovens das cidades do interior da província para a capital, a fim de freqüentar os bancos escolares expressava a condição típica dos filhos das camadas dominantes e dirigentes do Paraná. A origem social de Victor do Amaral permitia o ingresso nessas instituições de ensino.

Por outro lado, a instrução pública, logo após a criação da província paranaense (1853), contava com poucas cadeiras. O primeiro relatório do Presidente do Paraná, enviado a Assembleia em 15 de julho de $1854,{ }^{8}$ indicava a existência de vinte e oito cadeiras de primeiras letras, das quais vinte e cinco tinham professores. ${ }^{9}$

No Relatório apresentado em 1854, o Presidente asseverava que "a instrucção primaria convem derramar-se por toda a parte, fazel-a chegar a todas as localidades; he indeclinavel e urgentissima necessidade do povo" (RELATÓRIO..., 1854, p. 24-25). O desejo expresso pelo primeiro Presidente da província não foi acompanhado de políticas públicas para ampliação da escola primária, pois entre 1861 e 1871 o número de cadeiras/alunos praticamente não se alterou. Nos relatórios consultados a visão salvacionista da instrução primária era reproduzida, o que reafirma as pesquisas da historiografia da educação que demonstram que na segunda metade do século XIX houve "uma intensa discussão acerca da necessidade de escolarização da população, sobretudo das chamadas 'camadas inferiores da população"” (FARIA FILHO, 2003, p. 135).

Os relatórios dos inspetores da instrução pública do Paraná organizavam-se em três direções: exposição da importância da instrução popular, manifestação sobre o estado da educação escolar na Província e proposição de alternativas. Em 1871, Bento Fernandes de Barros expressava-se: "Educação popular! Tal é a questão de nossa epocha. [...] a instrucção primaria, sabia e largamente derramada, tal é o instrumento de uma educação 
que deve elevar a todos" (RELATÓRIO..., 1871, p. 4). Em contraposição ele reconhecia que "essa alta missão de educar o povo não é preenchida pelo actual ensino primário [...]" (p. 4). Na seqüência arrematava Barros, "a questão não é simplesmente de diffundir o ensino no seio das massas. Essa diffusão pressuppõe fazer reformas em nosso systema de educação popular" (RELATÓRIO..., 1871, p. 5). Em 1873, o Inspetor Geral João Franco de Oliveira Souza expressava que "nesta esperança província que ainda há pouco surgiu [...], a instrucção pública está ainda em grande atraso" (RELATÓRIO..., 1873, p. 2). Essas observações reiteram a indicação de Faria Filho de que havia uma "baixíssima capacidade de investimento das províncias [...]” (FARIA FILHO, 2003, p. 135).

A disparidade entre a retórica do discurso educacional e as políticas públicas implantadas era muito grande. Não obstante, é possível identificar que na segunda metade do século XIX, a administração pública paranaense criou um aparato burocrático que visava estabelecer um padrão mínimo para a instrução primária. Um exemplo dessa iniciativa foi a lei n. 30 de 12 de março de 1857 da província do Paraná, que no art. 14 determinou a criação de uma repartição estatística. Em 2 de novembro de 1861 foi criada essa repartição conforme atesta o relatório de 1862. No Relatório do Presidente da província do Paraná de 1874 localizamos o censo da população escolar, realizado em 1872. O referido censo indicava que a população com idade escolar total era de 24.908 crianças (6-15 anos), sendo 12.244 meninos e 12.684 meninas. A população que havia freqüentado a escola era de 2.558 meninos e 1.866 meninas. O contingente que não havia freqüentado a instrução primária pública era de 9.666 meninos e 10.818 meninas. Em termos percentuais $17,8 \%$ dessa população tinha freqüentado a escola. Ou seja, a maioria absoluta das camadas médias e populares estava fora dos espaços escolares.

Desse percentual de 17,8\% a grande maioria freqüentava apenas as séries iniciais da instrução primária $\mathrm{O}$ exemplo típico é a trajetória educacional de Francisco da Rocha Pombo (1857-1933), filho de professor primário de Morretes, que estudou as primeiras séries no distrito de Anhaia. A família de Rocha Pombo era de professores do litoral do Paraná, logo, prestadora de serviço educacional à própria oligarquia. $\mathrm{O}$ percurso escolar de Rocha Pombo se resumiu aos primeiros anos que freqüentou na escola dirigida pelo seu pai. Sua continuidade escolar foi feita posteriormente, culminando com a conclusão do curso de Direito (1912), no Rio de Janeiro, quando contava com 55 anos de idade. A exposição do contra exemplo é para explicitar que a trajetória escolar de Victor do Amaral tipifica a condição dos fillhos da elite econômica e política do Paraná.

\section{Do Colégio Jacob Müller ao Colégio Abílio da Corte}

Victor do Amaral ficou pouco tempo na capital do Paraná. Em seguida mudou-se para o Rio de Janeiro. Ele comenta que "depois de ter freqüentado esse colégio por mais de um ano, resolveu meu pai me levar, em meados de 1874, a Antonina com destino ao Rio de Janeiro" (SILVA, 1982, p. 24).

Na segunda metade do século XIX não era nada fácil e confortável viajar do Paraná à capital do Império. Nada de ferrovia, muito menos rodovia. O translado de Curitiba ao Rio de Janeiro se fazia pela hidrovia. Logo se percebe que a sua viagem de Curitiba ao Rio de Janeiro foi demorada. A primeira parte de sua partida foi da capital paranaense a Antonina. A distância atual entre essas duas cidades é de aproximadamente 80-90 quilômetros. Para os padrões de hoje não se trata de distância significativa. Mas naquele contexto se tratava de uma longa viagem. Não havia ainda a Ferrovia Curitiba-Paranaguá, muito menos Curitiba-Antonina. Essas ferrovias foram inauguradas em 1883 e 1892 respectivamente. Em 1874, não era a velha trilha da graciosa que remonta ao século XVIII. 
Já se tratava da estrada da graciosa com pavimentação. ${ }^{10}$ Tratava-se da primeira obra de escoamento a carro de boi da erva-mate para o Porto de Antonina, iniciada no primeiro governo da Província do Paraná.

Como sua família era detentora de capital social, o pequeno Victor ficou hospedado em Antonina na casa de amigos e parentes. Conta-nos Victor do Amaral que ficara hospedado na casa do Conselheiro Alves de Araújo, parente da família. Manuel Alves de Araújo era natural de Morretes, aliado da oligarquia dos Campos Gerais, particularmente porque foi casado com a filha do Barão dos Campos Gerais. A descrição autobiográfica indica que a família Amaral tinha boas relações com o grupo dominante da região dos Campos Gerais.

Após algum tempo de descanso na casa de Alves de Araújo foi levado a Paranaguá. Sua viagem era acompanhada pelo telegrafista curitibano Santo Elias Afonso da Costa. Em companhia desse senhor, Victor do Amaral foi embarcado em uma lancha até Paranaguá, onde aguardou por quatro dias a embarcação a vapor que se dirigia ao Rio de Janeiro. Após três dias de viagem chegara à capital do Brasil, quando foi entregue ao senhor Mattos Cruz. Nas palavras de Victor do Amaral, "esse bondoso amigo de meu pai acolheu-me com a mais generosa hospitalidade, me preparando para entrar para o afamado Colégio Abílio, onde ele já tinha internado um filho" (SILVA, 1982, p. 24). Mais uma vez o capital social e o capital econômico permitiram ao menino Victor ingressar em um espaço educativo destinado a uma parcela restrita da população.

Os colégios particulares constituíram-se, no século XIX, em opções para a elite política e econômica do Brasil, entre os quais estava o Colégio Abílio da Corte. Segundo Diane Valdez, Abílio iniciou

sua trajetória como proprietário e diretor de colégios em Salvador, em 1858, com o Ginásio Baiano e, no ano de 1870, transferiu-se para o Rio de Janeiro inaugurando o Colégio Abilio da Corte, que dirigiu até 1879. Em 1881, criou seu novo Colégio Abilio na cidade de Barbacena, em Minas Gerais, dirigindo-o até 1888 , quando retornou ao Rio de Janeiro com o Novo Colégio Abilio, inaugurado em parceria com seus filhos que, desde 1883, já dirigiam o estabelecimento. (VALDEZ, s.d., p. 1).

No início de julho de 1874, Victor do Amaral começou suas atividades no referido Colégio. Nas suas lembranças destaca a presença de Raul Pompéia, Olavo Bilac, Luiz Murat e Joaquim Dias da Rocha na época em que esteve nesse Colégio. No primeiro ano, Victor do Amaral afirma que foi aprovado "com distinção nos exames parciais de final de ano, havendo recebido, em pleno auditório dos alunos, um bondoso elogio do Dr. Abílio, dizendo: "menino, se você continuar assim, há de honrar o Paraná'" (SILVA, 1982, p. 25). No ano seguinte, informa o biografado que passou a estudar quase exclusivamente as línguas francesas, inglesa e latina, tendo apenas uma aula de português por semana. Próximo ao final do ano foi informado por seu pai de que os exames prestados no Colégio Abílio da Corte não tinham valor oficial, o que exigiria que ele realizasse exames preparatórios perante a Inspetoria de Instrução Pública da Corte. Assim ele procedeu, faltando dois meses para a última inscrição, iniciou seus estudos, privilegiando a área de Língua Portuguesa. Ele realizou seus exames perante uma banca de professores do Colégio D. Pedro II e foi aprovado.

O Ensino Secundário durante o Império brasileiro consistiu inicialmente na criação de aulas avulsas e particulares. Em seguida foram criadas escolas secundárias nas províncias do Brasil, como por exemplo, o Colégio de Jacob Müller de Curitiba. Foi nesse movimento que se estabeleceram em 1825 o "Ateneu do Rio Grande do Norte; em 1836, os 
Liceus da Bahia e da Paraíba; e, em 1837, o Colégio Pedro II, na Corte" (RIBEIRO, 2003, p. 50). O Liceu de Curitiba foi criado em 1846 pelo governo da Província de São Paulo, extinto em 1868 e restaurado em 1871.

O Presidente do Paraná, no relatório apresentado a Assembleia, manifestava-se que "quanto à [instrução] secundaria, vale mais tel-a concentrada em certos pontos, porem forte, do que diffundida e dispersa por diversas localidades, mas fraca; não ha vida, não ha progresso, nem emulação em estudos collocados na segunda das referidas condições" (RELATÓRIO..., 1854, p. 25). Apesar dessa declaração pouco se fez pela educação secundária. Até 1868, na província do Paraná, existia o Liceu de Curitiba e aulas avulsas no litoral. Evidencia essa observação o relatório referente ao ano de 1868, enviado a Assembleia em 1869, pelo Presidente da província: "reduz-se a instrucção secundaria na Província a existência de três aulas na capital: de arithmetica e geometria, de francez e de latim; e às aulas de latim e francez, nas cidades de Antonina e Paranaguá" (RELATÓRIO..., 1869, p. 11). Entre 1868 e 1871, o Liceu de Curitiba não funcionou. Para preencher essa lacuna a Província subvencionou o Colégio Jacob Muller. Até 1871, exceto as aulas avulsas, o Colégio de Müller era o único que oferecia ensino secundário. Atesta essa afirmação as observações do Relatório do Presidente da Província referente a 1871, "existe na Província um unico collegio de instrucção secundaria que é estabelecido nesta capital e dirigido pelo sr. Mueller" (RELATÓRIO..., 1872, p. 17).

Em 1871, o Liceu Público de Curitiba foi restaurado, ${ }^{11}$ o que representou a revogação da lei n. 167 de 7 de abril de 1868 que celebrou o contrato entre Jacob Müller e a província do Paraná para estabelecer um Colégio em Curitiba com subvenção pública. No Liceu público, no primeiro ano se organizaram as seguintes cadeiras: latim, francês, inglês, alemão, gramática filosófica, matemática elementar, filosofia, geografia e história. No entanto, esse projeto do liceu público não avançou. Em relatório do Presidente do Paraná (RELATÓRIO..., 1875, p. 35), atesta-se que "a situação financeira da província não permite por enquanto a fundação de um instituto que tenha por fim instruir seus alunnos em todas as disciplinas exigidas para o acesso às academias do Império independente de novos exames". Além disso, ressalta o relatório, "com os restos desorganizados do nosso antigo lyceu é evidente que não se póde preparar alunnos para os cursos superiores e nem o conseguiremos com os collegios de instrucção secundaria que esta capital possui e a cidade de Ponta Grossa e algumas aulas avulsas [...]” (RELATÓRIO..., 1875, p. 35).

Em termos gerais, é possível afirmar que o Ensino Secundário transitava entre a formação humana de nível médio e a preparação para ingressar no Ensino Superior. Em termos tipológicos, segundo Ribeiro,

a instrução secundária se caracterizou por ser predominantemente para alunos do sexo masculino, pela falta de organicidade (reunião espacial de antigas aulas régias), pelo predomínio literário, pela aplicação de métodos tradicionais e pela atuação da iniciativa privada. (RIBEIRO, 2003, p. 59).

Não obstante, assevera a autora,

os colégios particulares que conseguem a conciliação [formação humanista/preparação para o ensino superior], quer seja através de uma formação humana de tipo clássico [...], ou de uma formação moderna, como o Ginásio Baiano (1858-1871), sob a orientação de Abílio César Borges, são exceções e de existência bastante interrompida. (RIBEIRO, 2003, p. 61). 
Naquele contexto não existia um plano nacional de educação. A Corte se responsabilizou pelo ensino superior. Os níveis anteriores ficaram sob a responsabilidade das províncias. Na prática, os colégios secundários ficaram, em grande medida sob a coordenação de particulares, organizando-se a partir do currículo do Colégio Pedro II, bem como das cadeiras necessárias para ingressar no ensino superior.

No final de 1875, Victor do Amaral queria muito voltar ao Paraná para visitar sua família. No entanto, ele informa que o Dr. Abílio se contrapôs a essa viagem. O referido diretor teria dito que "não permitia que eu saísse do colégio, sem fazer o exame parcial das línguas que estava estudando" (SILVA, 1982, p. 27). Na continuidade desse diálogo, Victor teria dito que ele deveria dispensá-lo desses exames, pois já tinha feito exame de preparatório de português. No dizer de Victor do Amaral, o diretor mandou que "eu me recolhesse e fosse mudar a minha farda, embora eu lhe dissesse que o Inspetor do Colégio havia mandado entregar a minha roupa ao encarregado, que me havia acompanhado" (SILVA, 1982, p. 27). Essa narrativa se aproxima da preocupação moral e disciplinar dos colégios de Abílio. Sobre esse aspecto, Diane Valdez assevera que "um bom colégio, às vistas do diretor, não poderia abrir mão dos princípios morais, a base segura e incontestável de seus estabelecimentos" (VALDEZ, s. d., p. 6). Emenda a autora, "para manter a disciplina e a moralidade, era necessário manter a vigilância, que ficava por conta, sobretudo, dos censores, como aponta o Regimento Interno do Ginásio" (VALDEZ, s. d., p. 6).

A divergência entre Abílio Borges e Victor do Amaral narrada acima indica que o Colégio mantinha em seu currículo as disciplinas clássicas, mesmo com o processo de nacionalização do Programa do Colégio Pedro II. Sobre esse aspecto merece atenção a observação de Arlete Gasparello

Os Planos de Estudos e os Programas demonstram que as modificações introduzidas seguiram a tendência de torná-los cada vez mais nacionais. As diversas reformas de ensino apesar de criticadas como uma "cultura da reforma", procuraram responder, nas possibilidades da época, aos desafios colocados a uma ordem educacional que, ao valorizar a cultura clássica, estava em contradição com a tarefa de construção da nação, no espírito republicano e democrático, de valorização das coisas nacionais. Nesse processo, o ensino de Português conquistou espaço ao Latim e a História do Brasil cresceu em importância em relação à História Universal. (GASPARELLO, 2003, p. 4, sem grifo no original).

O episódio descrito por Victor do Amaral foi resolvido pela intervenção de um pai de aluno que residia em Niterói. "Esse cidadão compungido foi interceder por mim ao Dr. Abílio, que permitiu a minha retirada, abraçando-me e pedindo que não ficasse magoado com ele" (SILVA, 1982, p. 27). Conta-nos que, em razão do ocorrido no colégio, decidiu em conjunto com seu pai mudar de escola. Após suas férias nas colinas dos Campos Gerais, já no início de 1876, saiu da Lapa, a cavalo, em direção a Curitiba. Em Curitiba foi informado que a capital do Brasil estava acometida pelo surto de febre amarela. Sua família foi aconselhada a não enviar o infante para o Rio de Janeiro. Diante desse episódio, voltara da capital paranaense a sua cidade natal. Em 1872, de acordo com Gondra, Luiz Corrêa Azevedo, médico higienista, descrevia a cidade do Rio de Janeiros como "mal delineada, mal construída, mal ventilada, úmida, quente, fétida, insalubre, de arquitetura mesquinha e defeituosíssima no tocante aos trabalhos de higiene pública, polícia médica e educação higiênica [...]" (GONDRA, 2003, p. 52).

Apesar do problema de saúde pública, assevera Valdez: 
Muitos filhos de outras províncias eram obrigados a residir na Corte durante os longos anos em que se dedicavam às carreiras intelectuais, ficando sujeitos à deletéria ação de um clima diferente da localidade em que nasceram e foram criados, passando rapidamente a apresentar alteração profunda em sua constituição física. Os males não eram atribuídos somente ao clima da Corte, a organização dos internatos também concorria para aumentar as más condições da higiene. Portanto, para atrair alunos, era preciso inserir-se nos padrões ditados pelo controle da higiene. Para Abilio, isso não foi algo difícil, pois sua experiência e convicções pautavam-se nestes princípios. (VALDEZ, s. d., p.10).

No final de junho, já no período de inverno, momento em que o surto da febre tinha arrefecido, Victor do Amaral retornou ao Rio de Janeiro para retomar seus estudos. Conforme já conversado com seu pai, Senhor Seraphim, ele não continuaria no Colégio Abílio da Corte. Ele estava decidido a sair da escola e levava a correspondência de seu pai autorizando a retirada do restante de seus pertences que estavam no internato. Em conversa com Abílio não teve coragem de dizer a motivação verdadeira de sua saída. Indagado se seria por razão financeira, teria mentido que sim. O diretor do Colégio teria afirmado que o problema financeiro não seria impedimento para sua continuidade, pois estava disposto a conceder um desconto de $45 \%$ do valor da mensalidade. ${ }^{12}$ A situação desenrolou-se de uma forma que Victor permaneceu na escola. Sua narrativa informa que ele continuou no Colégio "até concluir os onze preparatórios, inclusive Filosofia, Retórica e Poética" (SILVA, 1982, p. 28). A autobiografia não indica em qual colégio estudaria Victor do Amaral se porventura saísse do Abílio da Corte. É possível especular que ele fosse enviado ao próprio Colégio Pedro II. Outra observação se refere ao motivo de sua pretensa saída do Colégio. Embora o biografado sustente que a motivação estava atrelada ao desentendimento com Abílio Borges, presumimos que a não equiparação do Abílio da Corte representava a principal razão de seu desejo de saída.

Pela exposição da historiografia da educação brasileira é possível observar o declínio dos saberes clássicos (línguas/história clássicas) em detrimento dos conhecimentos vernáculos (língua/história nacional). A esse respeito pronuncia-se Gasparello,

Os planos de estudos e programas de ensino demonstram a permanência, até o final do século, de uma concepção de cultura que privilegiava a erudição segundo as regras da eloquiência e da retórica. Mostram, ainda, a continuidade dos estudos em sete anos, que se iniciava com o ensino da Geografia, da Aritmética e do Latim; e terminava, no sétimo ano, com a Filosofia e a Retórica. (GASPARELLO, 2003, p. 4).

O conflito entre as cadeiras mais e menos prestigiadas se fazia presente nos relatórios dos presidentes da província do Paraná. A lei n. 33 de 13 de março de 1846, da Província de São Paulo, estabeleceu as aulas avulsas de ensino secundário na cidade de Paranaguá e o Liceu de Curitiba. Essa lei estabeleceu as aulas de francês e latim, nas quais estavam incluídas as cadeiras de filosofia racional e moral, história e geografia, geometria prática e noções gerais de mecânica aplicada às artes. Em Curitiba tinha também aula de Geometria e Aritmética. O valor pago aos professores para ensinar tais cadeiras variava, como por exemplo, o percentual de filosofia e línguas era 50\% maior do que geometria. $\mathrm{O}$ relatório do Presidente do Paraná sugere: "convem que desappareça quanto antes do orçamento provincial, a inferioridade de ordenado entre o professor de mathematicas e os 
de línguas" (RELATÓRIO..., 1869, p. 11). No mesmo relatório ele sustenta que "é tão obvia a superioridade do estudo das mathematicas, a sua necessidade indispensavel, a sua maior dificuldade comparada com a do ensino das línguas, que seria offender o vosso conhecido bom senso, querer fazer tal demonstração" (RELATÓRIO..., 1869, p. 11). O Presidente ao apresentar o orçamento determina que se invertam as condições, isto é, que o professor de matemática receba um valor maior que o de francês. E sugere a supressão da aula de latim.

No Colégio Abílio da Corte, Victor do Amaral cursou as disciplinas de cunho humanista, bem como as cadeiras que expressavam o projeto de educação moderna (matemáticas). ${ }^{13} \mathrm{O}$ movimento intelectual brasileiro, naquele contexto, já dialogava com os pensamentos positivista e cientificista ${ }^{14}$, o que explica o arrefecimento da concepção humanista clássica e a inserção de uma concepção atrelada às ciências modernas. E durante sua preparação prestou exames para ingressar no Ensino Superior. Conforme Gasparello,

Estes exames constituíam a forma anterior de intervenção centralizada pelo governo imperial nos estudos que vieram a constituir o secundário, $\mathrm{e}$ que deveriam ser realizados por todos que pretendessem seguir estudos superiores. Estes exames, regulamentados e fiscalizados pelo governo imperial, durante muito tempo foram apenas realizados na Corte, para onde se dirigiam os candidatos de todas as províncias do país. Os exames eram da responsabilidade do Ministério do Império, que nomeava a Banca de Exames e determinava a lista das matérias que os candidatos deveriam comprovar conhecimentos, que incluíam sempre o Latim. (GASPARELLO, 2003, p. 1).

O Colégio Pedro II materializou o controle do governo da Corte sobre esse grau de ensino, embora pela constituição fosse de responsabilidade das províncias. Sobre o lugar dessa instituição de ensino assevera Gasparello que "a fundação do Colégio de Pedro II, instituído como de instrução secundária, não interrompeu o sistema de preparatórios, prática tradicional que permaneceu por todo o primeiro século do Estado nacional brasileiro" (GASPARELLO, 2003, p. 1, itálico no original).

A origem social de Victor do Amaral permitia a ele o acesso aos espaços educativos com forte representação simbólica (reconhecimento). A formação secundária desse paranaense expressa um caso típico dos filhos da oligarquia brasileira, que buscava converter seu capital econômico em capital cultural. A estratégia dessas famílias consistia em pôr seus filhos nos colégios internos, cuja preparação direcionava ao ensino superior, por conseqüência, para ocupar os principais cargos na sociedade brasileira/paranaense. Nesse sentido, a ação de matricular Victor no Colégio Abúlio da Corte, o qual gozava de uma representação social muito positiva e, destinava-se a atender aos filhos das elites brasileiras, evidencia o lugar da família Amaral e Silva no cenário paranaense.

\section{À guisa de conclusão}

O objetivo deste artigo foi analisar a trajetória escolar de Victor Ferreira do Amaral, privilegiando sua origem familiar e sua inserção na escola primária (Colégio Jacob Müller) e na escola secundária (Colégio Abílio da Corte). Em outros termos, esta análise pretendeu discutir a trajetória dessa personalidade do oikos a scholé, buscando por meio de sua experiência de escolarização reconstituir também os contextos social, político, econômico, cultural, educacional da história paranaense. Essa narrativa inseriu-se na história intelectual, área pluridisciplinar, transitando entre uma abordagem sociológica (redes de 
sociabilidade) e um enfoque histórico (contextos). Em sentido mais preciso, transitou pelos enfoques dos contextos de produção de ideias (história), dos agentes socioprofissionais (sociologia) e das correntes de pensamento (filosofia).

Ao abordar a trajetória formativa de Victor do Amaral esta narrativa não deu o mesmo nível de tratamento aos aspectos histórico, sociológico e filosófico. Tal percepção é passível de identificar na própria organização da escrita. A rigor, objetivou-se enfatizar a perspectiva histórica e a sociológica, sem esquecer o movimento das correntes de pensamento. Ou seja, neste artigo interessou mais discutir a dimensão histórica (contextos) do que a dimensão teórica (ideias). Nesse aspecto, reconstituir as origens sociais, políticas, econômicos e culturais de Victor do Amaral se mostrou importante para entender a sua inserção na scholé, ou melhor, para explicar o processo de conversão de múltiplos capitais (econômico, social, político) em capital cultural nos três estados, particularmente no institucionalizado (diplomas). Desse modo, por meio da trajetória de Victor do Amaral foi possível compreender o movimento da elite política e econômica da Província do Paraná ao longo da segunda metade do século XIX que visava pôr seus filhos nas escolas de prestígio, preparando-os para ingressar no ensino superior e garantir suas presenças nos espaços públicos e privados de maior relevo do cenário paranaense. Em contrapartida, a instrução pública primária paranaense era incipiente, haja vista que mais de $80 \%$ da população escolar (6-15 anos) estava fora dos bancos escolares. Já a instrução secundária era praticamente inexistente, pois havia aulas avulsas na cidade de Paranaguá e o Liceu de Curitiba funcionava em condições muito precárias. Portanto, reconstituir a trajetória da escola primária e da escola secundária de Victor do Amaral representou historicizar as experiências educativas dos filhos dos fidalgos do Paraná.

\section{Referências}

CARVAlHO, J. M. de. A construção da ordem: a elite imperial. Teatro de sombras: a política imperial. Rio de Janeiro: Civilização Brasileira, 2003.

BOURDIEU, P. Por uma ciência das obras. In: Coisas ditas. Campinas: Papirus, 1996. p. 53-82.

ELIAS, N. O processo civilizador: formação do Estado e civilização. Rio de Janeiro: Jorge Zahar, 1993, v. 2.

FARIA FILHO, L. M. de. Instrução elementar no século XIX. In: LOPES, E. M. T. et al. 500 anos de educação no Brasil. Belo Horizonte: Autêntica, 2003. p. 134-150.

FERREIRA, J. C. V. O Paraná e seus municípios. Maringá: Memória Brasileira, 1996.

GASPARELLO, A. M. O paradoxo republicano: um modelo secundário nacional nos limites da descentralização. In: REUNIÃO ANUAL DA ANPED, 26, 2003, Poços de Caldas. Novo governo. Novas políticas? Anais... Poços de Caldas, 2003.

GONDRA, J. G. Medicina, higiene e educação escolar. In: LOPES, E. M. T. et al. 500 anos de educação no Brasil. Belo Horizonte: Autêntica, 2003. p. 519-550.

LIMA, E. C. Victor Ferreira do Amaral e Silva (o reitor de sempre). Curitiba: UFPR, 1982.

Revista HISTEDBR On-line, Campinas, n.41, p. 72-87, mar2011 - ISSN: 1676-2584 
OLIVEIRA, Maria C. M. Educação e sociedade: as escolas particulares no Paraná. Revista Contemporânea de Educação, Rio de Janeiro, v. 1, n. 1, abr./jun. 2006.

PARANÁ, Presidente (1853-1855: Vasconcellos). Relatório do presidente da Província do Paraná Zacarias de Góes e Vasconcellos na abertura da Assemblea Legislativa Provincial em 15 de julho de 1854. Curityba: Typ. Candido Martins Lopes, 1854.

PARANÁ, Presidente (1861-1863: Nogueira). Relatório do presidente da Província do Paraná Antônio Barbosa Gomes Nogueira na abertura da Assemblea Legislativa Provincial em 15 de fevereiro de 1862. Curitiba: Typ. Correio Official, 1862.

PARANÁ, Presidente (1868-1869: Fonseca). Relatório do presidente da Província do Paraná Antonio Augusto da Fonseca na abertura da Assemblea Legislativa Provincial em 6 de abril de 1869. Curityba: Typ. Candido Martins Lopes, 1869.

PARANÁ, Inspetor Geral da Instrução Pública. Relatório do inspetor geral da instrução pública da Província do Paraná JBento Fernandes de Barros apresentado ao Presidente da Província Venâncio José de Oliveira Lisboa em 29 de dezembro de 1870. Curityba: Typ. Candido Martins Lopes, 1871.

PARANÁ, Presidente (1870-1873: Lisboa). Relatório do presidente da Província do Paraná Venâncio José de Oliveira Lisboa na abertura da Assemblea Legislativa Provincial em 15 de fevereiro de 1872. Curityba: Typ. Viuva e Filhos de C. M. Lopes, 1872.

PARANÁ, Vice-Presidente (1873-1873: Guimarães). Relatório do vice-presidente da Província do Paraná Manoel Antonio Guimarães na abertura da Assemblea Legislativa Provincial em 17 de fevereiro de 1873. Curityba: Typ. Viuva Lopes, 1873.

PARANÁ, Inspetor Geral da Instrução Pública. Relatório do inspetor geral da instrução pública da Província do Paraná João Franco de Oliveira Souza apresentado ao Presidente da Província Venâncio José de Oliveira Lisboa em 31 de dezembro de 1872. Curityba: Typ. Viuva Lopes, 1873.

PARANÁ, Presidente (1873-1875: Abranches). Relatório do presidente da Província do Paraná Frederico José Cardoso de Araújo Abranches na abertura da Assemblea Legislativa Provincial em 15 de fevereiro de 1874. Curityba: Typ. Viuva Lopes, 1874.

PARANÁ, Presidente (1873-1875: Abranches). Relatório do presidente da Província do Paraná Frederico José Cardoso de Araújo Abranches na abertura da Assemblea Legislativa Provincial em 15 de fevereiro de 1875. Curityba: Typ. Viuva Lopes, 1875.

RIBEIRO, L. C. O mandonismo local e o movimento republicano. História: questões \& debates, Curitiba, v. 3, n. 4, p. 65-85, jun. 1982.

RIBEIRO, M. L. S. História da educação brasileira: a organização escolar. Campinas: Autores Associados, 2003. 


\title{
SILVA, V. F. do A. e. Minha infância escolar. In: LIMA, E. C. Victor Ferreira do
} Amaral e Silva (o reitor de sempre). Curitiba: UFPR, 1982. p. 23-29.

\author{
VALDEZ, Diane. Mens sana in corpore sano: os colégios do Dr. Abilio Cesar Borges, o \\ barão de macahubas (1858-1891). Disponível em: \\ http://www.histedbr.fae.unicamp.br/navegando/periodo_imperial.html. Acesso em: 27 mar. \\ 2010
}

WACHOWICZ, R. C. História do Paraná. Curitiba: Editora Gráfica Vicentina Ltda, 1977.

\footnotetext{
${ }^{1}$ Pesquisa financiada pelo CNPq.

${ }^{2}$ Prof. Dr. Névio de Campos, Universidade Estadual de Ponta Grossa - Programa de Pós-Graduação em Educação. Email: ndoutorado@yahoo.com.br
}

${ }^{3}$ Ao longo do texto, para nos referirmos a Victor Ferreira do Amaral e Silva, usaremos com mais frequência
Victor do Amaral por uma razão estilística e por ele ser mais conhecido por essa contração em seu nome.

${ }^{4}$ Não discutiremos neste artigo os espaços intelectuais e políticos ocupados por Victor do Amaral. Mas a título de informação indicamos que logo após concluir o ensino secundário ingressou na Faculdade de Medicina do Rio de Janeiro. Ao se formar em Medicina retornou ao Paraná, ocupando funções nas áreas de Instrução Pública e de Saúde Pública. Foi também deputado estadual e federal, bem como vice-governador do estado. No espaço acadêmico se notabilizou pela criação da Universidade do Paraná (1912).

${ }^{5}$ A referida biografia Minha infância escolar foi publicada na obra organizada por Eduardo Corrêa Lima. Portanto, a referência segue a paginação desta obra, mantendo-se a indicação Victor F. do Amaral e Silva.

${ }^{6}$ A obra A construção da ordem: a elite política imperial. Teatros de sombra: a política imperial de José Murilo de Carvalho retrata, em nível nacional, a disputa entre Partido Liberal e Partido Conservador.

${ }^{7}$ Foi fundado em 15 de fevereiro de 1869. Em 07 de abril de 1868 a lei n. 167 autorizou o Sr. Jacob Muller a criar uma escola primária e secundária em Curitiba. A referida lei também regulamentou a subvenção da Província à escola.

${ }^{8}$ Tomamos como referência para indicar os dados, a trajetória do personagem analisada neste artigo. Em 1853, inicia a história da Província do Paraná. Em 1862, ocorreu o nascimento de Victor do Amaral. Em 1869, seria o período próximo do início da escolarização de Victor. Em 1872 quando ele ingressou no Colégio de Jacob Muller. Em 1874, quando já estava no Rio de Janeiro. Tais dados são indicados para cruzar a educação popular com a educação da elite paranaense.

${ }^{9}$ Número de escolas/alunos entre 1861-1871: em 1861, 39 escolas, 1583 alunos; 1862, 37 escolas, 1455 alunos; 1863, 38 escolas, 1601 alunos; 1864, 41 escolas, 1605 alunos; 1865, 46 escolas, 1532 alunos; 1866, 47 escolas, 1642 alunos; 1867, 41 escolas, 1429 alunos; 1868, 49 escolas, 1671 alunos; 1869, 46 escolas, 1690 alunos; 1870, 50 escolas, 1690 alunos; 1871, 49 escolas, 1393 alunos. Em uma década o número de escolas e de alunos se alterou muito pouco, ou melhor, em 1871 o número de alunos era menor do que em 1861 (RELATÓRIO..., 1871).

${ }^{10}$ A ligação entre Curitiba e o litoral era feita por três caminhos: 1) Graciosa, ligando Curitiba a Antonina; 2) Itupava, ligando Curitiba a Morretes; 3) Arraial, entre São José dos Pinhais e Morretes (WACHOWICZ, 1977, p. 75). 
${ }^{11}$ Em 1846, foi criado o Liceu de Curitiba. Em 1868, foi extinto o referido Liceu, passando a ter cadeiras avulsas de latim e francês sob a supervisão do mesmo professor. Em 1871, foi restabelecido o antigo Liceu. Em 1876, passou a se denominar Instituto Paranaense. Em 1892, passou a se chamar Gymnasio Paranaense. Em 1900, foi equiparado ao Colégio Pedro II.

${ }^{12}$ A família de Victor do Amaral pagava 180 contos de reis por trimestre; com o desconto passou a pagar 100 contos de reis.

${ }^{13}$ As áreas ensinadas eram português, francês, inglês, latim, alemão, matemática, geografia e cosmologia, filosofia, retórica e poética, história, ciências físicas e naturais, instrução cívica.

${ }^{14}$ Não exploraremos neste texto as doutrinas teóricas e filosóficas presentes naquele contexto. Sugerimos consultar a obra A ilustração brasileira e a idéia de universidade de Roque Spencer Maciel de Barros.

Recebido em 28/10/2010

Aprovado em 10/01/2011 